Gustavo Silva Araújo

\title{
Análise do Modelo de Apreçamento de Opções GARCH em Opções de Compra da Telebras
}

Dissertação de Mestrado

Dissertação apresentada como requisito parcial para obtenção do grau de Mestre pelo Programa de Pósgraduação em Administração de Empresas do Departamento de Administração da PUC-Rio. Aprovada pela Comissão Examinadora abaixo assinada.

Orientador: Prof. Antonio Carlos Figueiredo Co-orientador: Prof. Eduardo Facó Lemgruber 


\title{
Gustavo Silva Araújo
}

\section{Análise do Modelo de Apreçamento de Opções GARCH em Opções de Compra da Telebras}

Dissertação apresentada como requisito parcial para obtenção do grau de Mestre pelo Programa de Pósgraduação em Administração de Empresas do Departamento de Administração da PUC-Rio. Aprovada pela Comissão Examinadora abaixo assinada.

\author{
Prof. Antonio Carlos Figueiredo \\ Orientador \\ Departamento de Administração, PUC-Rio \\ Prof. Eduardo Facó Lemgruber \\ Co-orientador \\ Coppead/UFRJ
}

Prof. Octávio Manuel Bessada Lion Banco Central do Brasil

Profa. Zélia M. de Lossio e Seiblitz Coordenadora Setorial de Pós-Graduação do Centro de Ciências Sociais - PUC-Rio 
Todos os direitos são reservados. É proibida a reprodução total ou parcial do trabalho sem autorização da universidade, da autora e do orientador

\section{Gustavo Silva Araújo}

Graduou-se em Engenharia de Produção na PUC-Rio em 1996. Cursou Análise de Sistemas na CCE/PUC-Rio em 1999. Trabalha no Departamento de Pesquia do Banco Central do Brasil na área de Finanças - Risco de Mercado.

Ficha Catalográfica

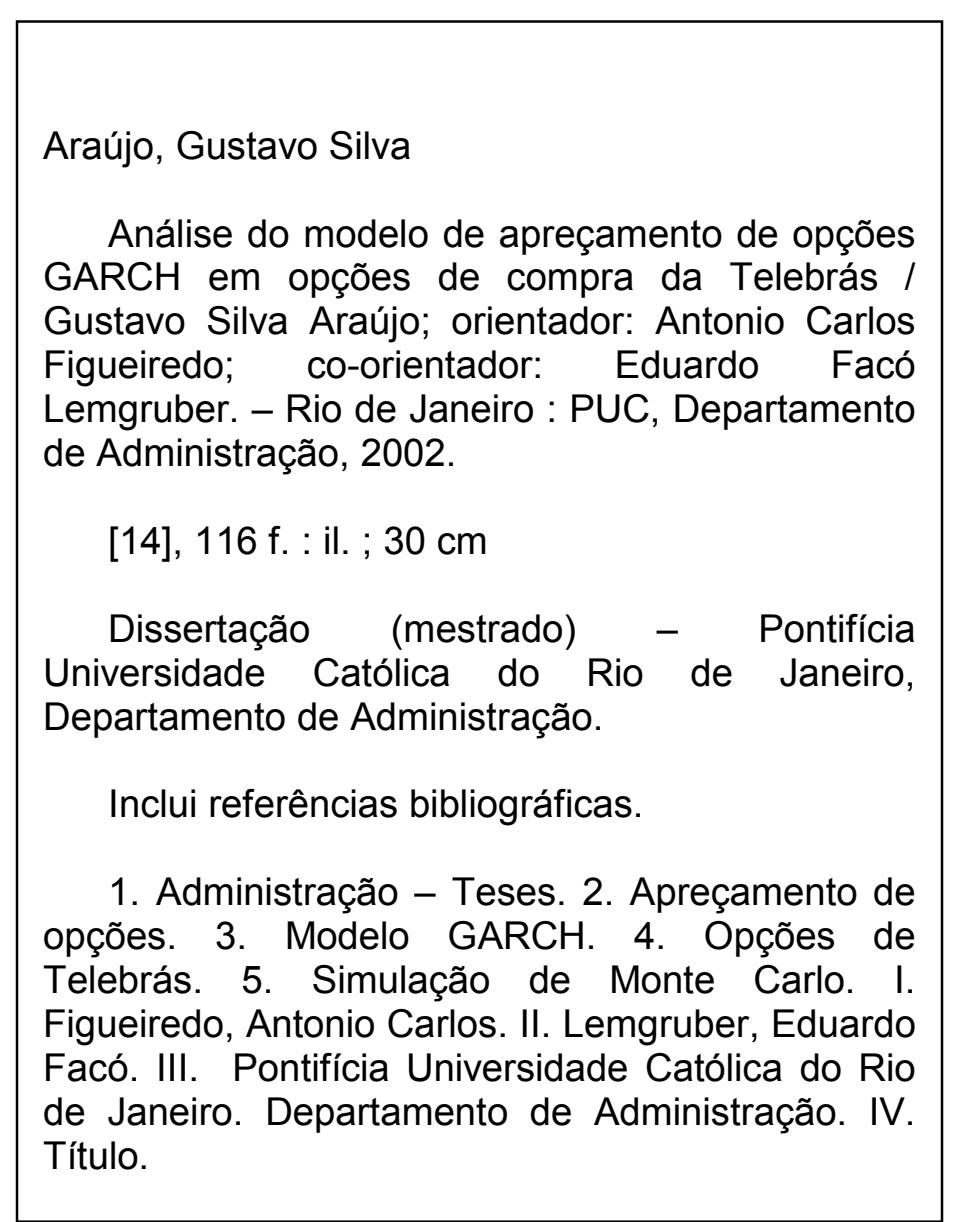

CDD: 658 


\section{Agradecimentos}

Aos meus pais e irmã, por sempre me apoiarem.

Aos Professores Figueiredo e Facó pelo estímulo e confiança depositada.

Ao Banco Central do Brasil, por ter incentivado a execução do Mestrado.

Ao colega Cláudio Barbedo, pela generosa colaboração.

Ao membro da banca, Prof. Octávio Manuel Bessada Lion. 


\section{Resumo}

Araújo, Gustavo Silva; Figueiredo, Antonio Carlos (Advisor); Lemgruber, Eduardo Facó (Co-advisor). Analysis of The GARCH Option Pricing Model using Telebras Calls. Rio de Janeiro, 2002. 131p. MSc.Dissertation - Departamento de Administração, Pontifícia Universidade Católica do Rio de Janeiro.

Este trabalho procura confirmar a hipótese de o modelo de apreçamento de opções GARCH reduzir alguns dos já amplamente estudados vieses do modelo de Black \& Scholes, utilizando opções de compra da Telebras no período julho de 1995 a junho de 2000. Para isso, comparam-se os preços encontrados por intermédio do modelo GARCH com os do modelo de Black \& Scholes, cotejando-os com os preços de mercado. Os resultados indicaram que o modelo GARCH foi capaz de diminuir alguns dos vieses, principalmente para opções fora-do-dinheiro com curto tempo para o vencimento. Desta forma, o modelo GARCH se mostrou uma alternativa eficaz ao modelo de Black \& Scholes, sobretudo para opções com pouca liquidez, nas quais não é possível a utilização da volatilidade implícita da equação de Black \& Scholes.

\section{Palavras-Chave}

Apreçamento de opções; modelo GARCH; simulação de monte carlo; opções de telebras. 


\section{Abstract}

Araújo, Gustavo Silva; Figueiredo, Antonio Carlos (Advisor); Lemgruber, Eduardo Facó (Co-advisor). Analysis of The GARCH Option Pricing Model using Telebras Calls. Rio de Janeiro, 2002. 131p. MSc.Dissertation - Departamento de Administração, Pontifícia Universidade Católica do Rio de Janeiro.

This study attempts to confirm the hypothesis that the GARCH option pricing model reduces some of the well-documented biases associated with the Black \& Scholes model, using Telebras calls in the period of July 1995 to June 2000. For this purpose, the prices obtained by the GARCH model are compared with the ones obtained by the Black \& Scholes model, and both of them are checked with the market prices. The results of this research indicate that the GARCH model is able to lessen some biases, specially for out-of-the-money options with short maturity. Thus, the GARCH model is an efficient alternative to the Black \& Scholes model, mainly for options with low liquidity, in which it is not possible to use the implicit volatility of the Black \& Scholes equation.

\section{Keywords}

Option pricing; GARCH model; monte carlo simulation; telebras calls 


\section{Sumário}

$\begin{array}{ll}\text { Lista de gráficos } & 10\end{array}$

$\begin{array}{ll}\text { Lista de tabelas } & 11\end{array}$

1 Introdução 15

$\begin{array}{lll}1.1 & \text { Objetivos } & 17\end{array}$

$\begin{array}{lll}1.2 & \text { Relevância do Estudo } & 18\end{array}$

$\begin{array}{lll}1.3 & \text { Delimitação do Estudo } & 19\end{array}$

2 Revisão Bibliográfica 20

2.1 Modelo de Apreçamento de Opções GARCH 20

2.2 Modelo de Apreçamento de Opções GARCH x Modelo de $\begin{array}{ll}\text { Black\&Scholes (B\&S) } & 24\end{array}$

2.3 Aplicações do Modelo de Apreçamento de Opções GARCH 26

$3 \quad$ Metodologia e Amostra 38

3.1 Seleção do Período e da Amostra 38

3.2 Cálculo da Curva da Taxa de Juros Pré-Fixada 42

3.3 Cálculo das Volatilidades 44

3.3.1 Volatilidade Histórica 44

3.3.2 Volatilidade Calculada pelo Método GARCH 44

3.3.3 Volatilidade Implícita da Fórmula de Black\&Scholes 45

3.4 Apreçamento das Observações de Opções pelo Modelo de Black\&Scholes $\quad 45$

3.5 Apreçamento das Observações de Opções pelo Modelo de GARCH 46 
3.5.1 Escolha do Método GARCH para Cada Semestre 46

3.5.2 Estimação dos Parâmetros de GARCH Dia-a-Dia 50

3.5.3 Apreçamento das Opções 51

3.6 Medidas de Erro e Testes Estatísticos 52

4 Apresentação e Análise dos Resultados da Comparação entre os Modelos de Black\&Scholes e GARCH 54

4.1 Influência do Número de Negócios no Apreçamento das Opções 54

4.2 Influência do Tempo para o Vencimento no Apreçamento das Opções

4.3 Erros Médios dos Modelos de Apreçamento de Opções para Toda a Amostra e em Relação à Razão entre o Preço da Telebras e o Valor Presente do Preço de Exercício

4.4 Erros Médios dos Modelos de Apreçamento de Opções em Cada Semestre para Todas as Observações de Opções e em Relação à Razão entre o Preço da Telebras e o Valor Presente do Preço de Exercício

4.5 Sub-apreçamento e Super-apreçamento dos Modelos para Toda a Amostra

4.6 Sub-apreçamento e Super-apreçamento dos Modelos em Relação ao Preço de Mercado, ao Tempo para Vencimento e à Razão entre o Preço da Telebras e o Valor Presente do Preço de Exercício 73

4.6.1 Com a Volatilidade Calculada Por Um Processo GARCH 73

4.6.2 Com a Volatilidade Implícita da Fórmula de B\&S do Dia Útil Imediatamente Anterior

5 Conclusão

6 Referências Bibliográficas 
Anexo 1 - Aproximações Realizadas para o Cálculo da Taxa Pré-Fixada do Dia do Pregão ao Dia de Vencimento da Opção

Anexo 2 - Estimativa dos Métodos GARCH para Escolha de Qual Método Seria Utilizado em Cada Semestre 108

Anexo 3 - Programas para a Escolha do Método GARCH a ser Utilizado no Semestre

Anexo 4 - Programas para Obtenção dos Parâmetros de GARCH a Cada Dia

Anexo 5 - Função para a Obtenção do Preço da Opção pelo Modelo GARCH

Anexo 6 - Tabelas da Relação Entre o Número de Negócios das Observações de Opções e os Erros dos Modelos de Apreçamento GARCH e B\&S, Utilizando-se as Volatilidades Histórica, Implícita de B\&S e a Calculada por Um Processo GARCH 


\section{Lista de gráficos}

Gráfico 1 - Relação $n^{\circ}$ de Negócios X Erros Médios dos Modelos no Apreçamento de Opções de B\&S e GARCH, Utilizando a Volatilidade Histórica

Gráfico 2 - Relação $n^{\circ}$ de Negócios X Erros Médios dos Modelos no Apreçamento de Opções de B\&S e GARCH, Utilizando a Volatilidade Calculada por um Processo GARCH 56

Gráfico 3 - Relação $n^{\circ}$ de Negócios X Erros Médios dos Modelos no Apreçamento de Opções de B\&S e GARCH, Utilizando a Volatilidade Implícita da Fórmula de B\&S do Dia Útil Anterior

Gráfico 4 - Relação entre o Tempo para Vencimento e os Erros Médios do Apreçamento dos Modelos de B\&S e GARCH, Utilizando a Volatilidade Histórica

Gráfico 5 - Relação entre o Tempo para Vencimento e os Erros Médios do Apreçamento dos Modelos de B\&S e GARCH, Utilizando a Volatilidade GARCH

Gráfico 6 - Relação entre o Tempo para Vencimento e os Erros Médios do Apreçamento dos Modelos de B\&S e GARCH, Utilizando a Volatilidade Implícita de B\&S 


\section{Lista de tabelas}

Tabela 1 - Divisão da Amostra em Semestres e as Características dos Retornos da Telebras para cada Período

Tabela 2 - Quantidade de Observações de Preços de Opções de Compra da Telebras por Semestre

Tabela 3 - Quantidade de Observações de Opções de Compra da Telebras em Relação à Razão entre o Preço do Ativo-Objeto e o Valor Presente do Preço de Exercício da Opção

Tabela 4 - Semestres em Que a Amostra é Dividida, com seu Total de Dias Úteis e com a Janela para a Estimação dos Parâmetros de GARCH

Tabela 5 - Processo GARCH Selecionado para Cada Semestre e a Justificativa para a Escolha

Tabela 6 - Relação Entre o Tempo para o Vencimento (em dias úteis) e os Erros Médios das Observações das Opções no Apreçamento pelos Modelos de GARCH e B\&S, Utilizando a Volatilidade Histórica

Tabela 7 - Relação Entre o Tempo para o Vencimento (em dias úteis) e os Erros Médios das Observações das Opções no Apreçamento pelos Modelos de GARCH e B\&S, Utilizando a Volatilidade Calculada por um Processo GARCH

Tabela 8 - Relação Entre o Tempo para o Vencimento (em dias úteis) e os Erros Médios das Observações das Opções no Apreçamento pelos Modelos de GARCH e B\&S, Utilizando a Volatilidade Calculada Implícita de B\&S do Dia Útil Anterior

Tabela 9 - Erros Médios dos Modelos de GARCH e B\&S, Utilizando a Volatilidade Histórica, para Toda a Amostra 
Tabela 10 - Erros Médios dos Modelos de GARCH e B\&S, Utilizando a Volatilidade Calculada por um Processo GARCH, para Toda a Amostra 63

Tabela 11 - Erros Médios dos Modelos de GARCH e B\&S, Utilizando a Volatilidade Implícita da Fórmula de B\&S do Dia Útil Imediatamente Anterior, para Toda a Amostra

Tabela 12 - Erros Médios dos Modelos de GARCH e B\&S, Utilizando a Volatilidade Histórica, em Relação à Razão entre o Preço da Telebras e o Valor Presente do Preço de Exercício

Tabela 13 - Erros Médios dos Modelos de GARCH e B\&S, Utilizando a Volatilidade Calculada por um Processo GARCH, em Relação à Razão entre o Preço da Telebras e o Valor Presente do Preço de Exercício 65

Tabela 14 - Erros Médios dos Modelos de GARCH e B\&S, Utilizando a Volatilidade Implícita da Fórmula de B\&S do Dia Útil Imediatamente Anterior, em Relação à Razão entre o Preço da Telebras e o Valor Presente do Preço de Exercício 65

Tabela 15 - Erros Médios dos Modelos de GARCH e B\&S, Utilizando a Volatilidade Histórica, para Todas as Observações de Opções e em Relação à Razão entre o Preço da Telebras e o Valor Presente do Preço de Exercício para Cada Semestre

Tabela 16 - Erros Médios dos Modelos de GARCH e B\&S, Utilizando a Volatilidade calculada por um processo $\mathrm{GARCH}$, para Todas as Observações de Opções e em Relação à Razão entre o Preço da Telebras e o Valor Presente do Preço de Exercício para Cada Semestre

Tabela 17 - Erros Médios dos Modelos de GARCH e B\&S, Utilizando a Volatilidade Implícita de Black\&Scholes, para Todas as Observações de Opções e em Relação à Razão entre o Preço da Telebras e o Valor Presente do Preço de Exercício para Cada Semestre

Tabela 18 - Sub-apreçamento e Super-apreçamento dos Modelos de B\&S e GARCH para Toda a Amostra 
Tabela 19 - Percentual de Observações de Opções Sub-apreçadas e Super-apreçadas e Seus Erros Médios para Observações de Opções Fora-do-Dinheiro para Cada Semestre, para os Intervalos de Tempo para Vencimento 1 a 15, 16 a 30 e mais de 30 Dias Úteis, para o Modelo B\&S Utilizando a Volatilidade Calculada por Um Processo GARCH

Tabela 20 - Percentual de Observações de Opções Sub-apreçadas e Super-apreçadas e Seus Erros Médios para Observações de Opções Fora-do-Dinheiro para Cada Semestre, para os Intervalos de Tempo para Vencimento 1 a 15, 16 a 30 e mais de 30 Dias Úteis, para o Modelo GARCH Utilizando a Volatilidade Calculada por Um Processo GARCH 75

Tabela 21 - Percentual de Observações de Opções Sub-apreçadas e Super-apreçadas e Seus Erros Médios para Observações de Opções NoDinheiro para Cada Semestre, para os Intervalos de Tempo para Vencimento 1 a 15, 16 a 30 e mais de 30 Dias Úteis, para o Modelo B\&S Utilizando a Volatilidade Calculada por Um Processo GARCH 76

Tabela 22 - Percentual de Observações de Opções Sub-apreçadas e Super-apreçadas e Seus Erros Médios para Observações de Opções NoDinheiro para Cada Semestre, para os Intervalos de Tempo para Vencimento 1 a 15, 16 a 30 e mais de 30 Dias Úteis, para o Modelo GARCH Utilizando a Volatilidade Calculada por Um Processo GARCH 77 Tabela 23 - Percentual de Observações de Opções Sub-apreçadas e Super-apreçadas e Seus Erros Médios para Observações de Opções Dentro-do-Dinheiro para Cada Semestre, para os Intervalos de Tempo para Vencimento 1 a 15, 16 a 30 e mais de 30 Dias Úteis, para o Modelo B\&S Utilizando a Volatilidade Calculada por Um Processo GARCH $\quad 79$

Tabela 24 - Percentual de Observações de Opções Sub-apreçadas e Super-apreçadas e Seus Erros Médios para Observações de Opções Dentro-do-Dinheiro para Cada Semestre, para os Intervalos de Tempo para Vencimento 1 a 15, 16 a 30 e mais de 30 Dias Úteis, para o Modelo GARCH Utilizando a Volatilidade Calculada por Um Processo GARCH 80 Tabela 25 - Percentual de Observações de Opções Sub-apreçadas e Super-apreçadas e Seus Erros Médios para Observações de Opções 
Fora-do-Dinheiro para Cada Semestre, para os Intervalos de Tempo para Vencimento 1 a 15, 16 a 30 e mais de 30 Dias Úteis, para o Modelo B\&S Utilizando a Volatilidade Implícita de B\&S do Dia Útil Anterior

Tabela 26 - Percentual de Observações de Opções Sub-apreçadas e Super-apreçadas e Seus Erros Médios para Observações de Opções Fora-do-Dinheiro para Cada Semestre, para os Intervalos de Tempo para Vencimento 1 a 15, 16 a 30 e mais de 30 Dias Úteis, para o Modelo GARCH Utilizando a Volatilidade Implícita de B\&S do Dia Útil Anterior 83 Tabela 27 - Percentual de Observações de Opções Sub-apreçadas e Super-apreçadas e Seus Erros Médios para Observações de Opções NoDinheiro para Cada Semestre, para os Intervalos de Tempo para Vencimento 1 a 15, 16 a 30 e mais de 30 Dias Úteis, para o Modelo B\&S Utilizando a Volatilidade Implícita de B\&S do Dia Útil Anterior 84 Tabela 28 - Percentual de Observações de Opções Sub-apreçadas e Super-apreçadas e Seus Erros Médios para Observações de Opções NoDinheiro para Cada Semestre, para os Intervalos de Tempo para Vencimento 1 a 15, 16 a 30 e mais de 30 Dias Úteis, para o Modelo GARCH Utilizando a Volatilidade Implícita de B\&S do Dia Útil Anterior 85 Tabela 29 - Percentual de Observações de Opções Sub-apreçadas e Super-apreçadas e Seus Erros Médios para Observações de Opções Dentro-do-Dinheiro para Cada Semestre, para os Intervalos de Tempo para Vencimento 1 a 15, 16 a 30 e mais de 30 Dias Úteis, para o Modelo B\&S Utilizando a Volatilidade Implícita de B\&S do Dia Útil Anterior

Tabela 30 - Percentual de Observações de Opções Sub-apreçadas e Super-apreçadas e Seus Erros Médios para Observações de Opções Dentro-do-Dinheiro para Cada Semestre, para os Intervalos de Tempo para Vencimento 1 a 15, 16 a 30 e mais de 30 Dias Úteis, para o Modelo GARCH Utilizando a Volatilidade Implícita de B\&S do Dia Útil Anterior 88 